\title{
USE OF TECHNOMOLECULAR SILVER PREPARATIONS IN COMPLEX TREATMENT OF INFECTED WOUNDS
}

DOI: 10.36740/WLek202003135

\author{
Stepan S. Filip, Rudolf M. Slivka, Yuriy P. Skripinets, Andriy M. Bratasyuk, Olena V. Fomenko-Luchinets
}

UZHHOROD NATIONAL UNIVERSITY, UZHHOROD, UKRAINE

\begin{abstract}
The aim: To improve the results of treatment of infected wounds.

Materials and methods:The clinical material is based on clinical observation and treatment of 29 patients with in fected wounds, whose treatment included combination drugs of local action on the basis of techno-molecular silver (in particular «(adefort-Spray»), by application to the wound surface.

Results: Wound microbial factor, dynamics of wound process, indicators of immune status were evaluated: localadaptive immunity, atopic reactions.

Conclusions: High efficiency of treatment was observed regardless of the phase of the wound process, which allowed to accelerate wound repair and stimulate the processes of regeneration, strengthen local adaptive immunity, prevent atopic reactions.
\end{abstract}

KEY WORDS: wound, silver ions, regeneration, local immunity, atopic reactions

Wiad Lek. 2020;73(3):584-588

\section{INTRODUCTION}

In recent years, the problem of treating infected wound injuries has augmented significantly, both in the world and in Ukraine in particular. Such an amplification of the problem is evidenced by the increase in the number of surgical patients with purulent-inflammatory diseases by up to $35-40 \%$, and the total lethality from purulent infection by up to $42-60 \%[1,2]$. The proportion of surgical wound infection accounts for up to $15 \%$ of the total number of nosocomial infections $[1,2,3]$.This is primarily due to the increase in the number of patients with vascular disorders (atherosclerosis, chronic venous insufficiency), to the rapid development of antibiotic-resistant microflora and to a significant decrease in human immune protection, since the mutagenic effect of antibiotics on pathogenic microflora has led to a change in the etiological structure of purulent surgical infection and biological properties of the microbial cell, and environmental contamination has led to the immunobiological resistance of the macroorganism [1,2,4]. Modification of virulence and resistance of microorganisms require improvement of method sandways of surgical treatment of purulent-necrotic processes against the background of the burdened general condition of the patient. The severity of purulent-necrotics of ttissue disease in most patients is due to the additional impact of major background pathology, such as chronic intoxication, decompensation of comorbid somatic diseases, poly-organ dysfunction syndrome, and secondary immunodeficiency $[4,5]$.

In this regard, drugs of local action of the antibiotic spectrum have been surely losing their strong positions until recently [4,5]. In such conditions, the situation arises when the possibilities of correction of metabolic disorders and treatment of the underlying disease, as well as carrying out systemic etiotropic antibacterial therapy, are significantly limited $[5,6]$ due to the deterioration of the detoxification potential, the compensatory and adaptive properties of the organism. Therefore, the need to improve the effectiveness of local treatment of the cell of destruction and purulent inflammation is increasing. In this regard, the agents of local action, the antibiotic spectrum, are definitely losing their until recently strong positions. The current level of theoretical and practical advances in surgery allows us to look from new perspectives on the problem of improving the effectiveness of therapeutic agents intended for the treatment of wounds. This allows a differentiated approach to the choice of treatment methods, taking into account the pathogenesis and phases of the wound process, as well as the nature of the pathogen and its sensitivity to drugs. $[5,6]$.

\section{THE AIM}

The goal of this study was to analyze the features of pathogenesis and the course of the wound process of modern infected wounds; to improve the results of treatment of infected wounds by the use of preparations based on techno-molecular silver, with the purpose of effective suppression of microflora, limitation of inflammation, purification from purulent-necrotic content in the short term taking into account the phases of the wound process. Another goal was to improve local adaptive immunity and prevent the development of atopic reactions. 


\section{MATERIALS AND METHODS}

The clinical material is based on the clinical observation and treatment of 39 patients with infected wounds of different origins at the Clinic of the Department of General Surgery and Surgical Department of the Clinical Hospital "Uzhhorod Regional Hospital" for 2018-2019.

In 17 patients, chronic vascular disorders of the lower extremities were the cause of the wound injury. In 14 patients the cause were purulent-necrotic lesions of subcutaneous fat such as carbuncles, boils, abscesses. In 8 patients, burn wounds were due to thermal damage. The control group consisted of 10 patients with infected wounds, whose treatment was carried out by the classical method, without the use of silver preparations. For the surgical treatment of wounds and trophic ulcers, antiseptic solutions $(0.02 \%$ solution of decasan, $0.05 \%$ solution of rivanol, $0.5 \%$ aqueous solution of chlorhexidine bigluconate locally) and various powder application sorbents were used in the exudation phase.

\section{RESULTS AND DISCUSSION}

Bacteriological examination of the content of wounds revealed a predominance of pathogenic Staphylococcus aureus and its associations, in particular with Proteus, Escherichia coli or Pseudomonas aeruginosa (Fig.1).

Inthecontrol group, the granulation tissue developed an average of $6.5 \pm 0.42$ days. Of these, ten (29.4\%) revealed juicy granulations, sixteen $(47.0 \%)$ showed brittle (a small number of vessels, a lot of amorphous substance and cellular elements), and juicy granulations (a considerable number of newly formed ones). Vessels with a small number of cellular elements) in these patients appeared on the average only on $8,2 \pm 0,29$ days. Eight patients $(23.6 \%)$ had no granulation at all within 12 days, and appeared with an average on $16.59 \pm 0.55$ days. The wounds were cleaned by an average of $5.15 \pm$ 0.35 days, their size decreased daily (measurements were performed with a sterile centimeter tape) by an averageof $1.1 \pm 0.07 \mathrm{~cm}$.

In the treatment of the main group (19 patients), along with the background use of conventional therapeutic measures of local and general influence, combination drugs of local action, on the basis of technomolecular silver (in particular "Kadefort-Spray"), were applied to the woundsurface once a day. Due to the presence of silver, kaolin, sodium hyaluronate and chlorhexidine ions in its composition, Kadefort-Spray allows to stimulate and accelerate regenerative processes against the background of stable antiseptic and dehydration effect (Fig. 2, 3, 4).

Control of therapeutic dynamics was based on the course of the wound process as compared toaverage wound healing data, which was halved. We observed faster appearance of mature granulation tissue and of signs of marginal and islet epithelialization.

It was noted that due to its content of hyaluronic acid, kaolin and technomolecular silver, "Cadefort-spray" has a positive effect on the wound process irrespective of phase and destroys microorganisms at the cytological level. According to the bacteriological study, the disappearance of pathogenic microorganisms in the wound was observed at 7-10 days of the healing process. Due to the film-forming, Cadefort Spray protects the wound surface from further daily mechanical damage and has an indirect analgesic effect, which is especially important in the treatment of burn wounds (Fig. 5, 6).

The level of body's defenses was assessed by indicators of the immune status of the organism, which was the evidence base for the study. The number of T-helpers (CD-4), T-suppressors (CD-8), their ratio (Tx (CD-4) / Tc (CD-8), as an indicator of local adaptive immunity, and $\operatorname{IgE}$ dynamics as a marker were taken into account. The analysis of immunological data showed that patients with chronic skin damage demonstrated damage of their immune status.

In these patients, against the background of a decrease in the total number of lymphocytes, the following were noted: a sharp decrease in the amount of Tx (CD-4) with a moderate decrease in Tc (CD-8), a corresponding decrease in their ratio, and a decrease in the level of Ig E.

After treatment, there is a tendency of normalization of the CD-4 / CD-8 ratio (Fig.7) and an increase in IgE levels (Fig.8), which indicates an increase in local adaptive immunity and absence of atopic reactions.

\section{CONCLUSION}

Intoday's treatment of patients with infected wounds, it is necessary to take into account the rapid development of antibiotic-resistant microorganisms and the global weakening of the immune protection of the population. The choice of modern topical applications makes it possible to significantly improve the results of treatment, with minimal financial costs and minimal toxic effects on the patient's body, to reduce the patient's stay in hospital, to increase local adaptive immunity, and to prevent the development of atopic reactions.

\section{REFERENCES}

1. Blatun L.A. Local medicamental treatment of wounds. Surgery of N.Y. Pyrohova. 2011;4:51-59.

2. Datsenko B.M, BielovS.H., Tamm T.I. Mistseve likuvannia infikovanykh ran [Local treatment of infected wounds] https://www.pharmencyclopedia. com.ua/article/1484/ (in Ukr).

3. Shablovskaya T.A, Panchnenkov D.N. Suchasni pidkhody do likuvannia hniinykh ran. Nevyrisheni problem. [Modern approaches to complex treatment of purulent-necrotic diseases of soft tissues.] Journal of Experimental and Clinical Surgery. 2013;6(4):498-507.

4. Shaprynskyi V.0, Skalskyi S.S, Palamarchuk S.V. Treatment of purulent wounds with wound dressing on a foamy basis with Hydrofiber technology. Khirurgiia. 2017;(7):49-53. doi: 10.17116/ hirurgia2017749-53.

5. Hosan K, Makin I, Skiba J. Antibacterial efficacy testing of a bioelectric wound dressing against clinical wound pathogens. The open microbiology journal. 2014;8:15-21. 


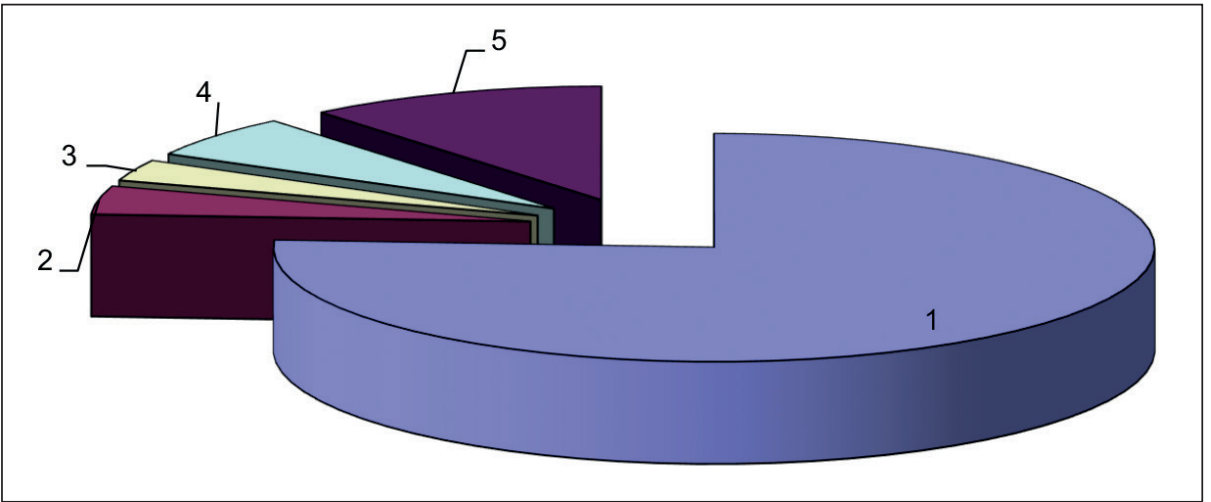

Fig. 1. The nature of the microflora in wounds: 1 - Staphylococci (76\%); 2 - Pseudomonas aeruginosa (6\%); 3 - Proteus (3\%);

4 - Escherichia coli (4\%); 5 - microbial associations (11\%).

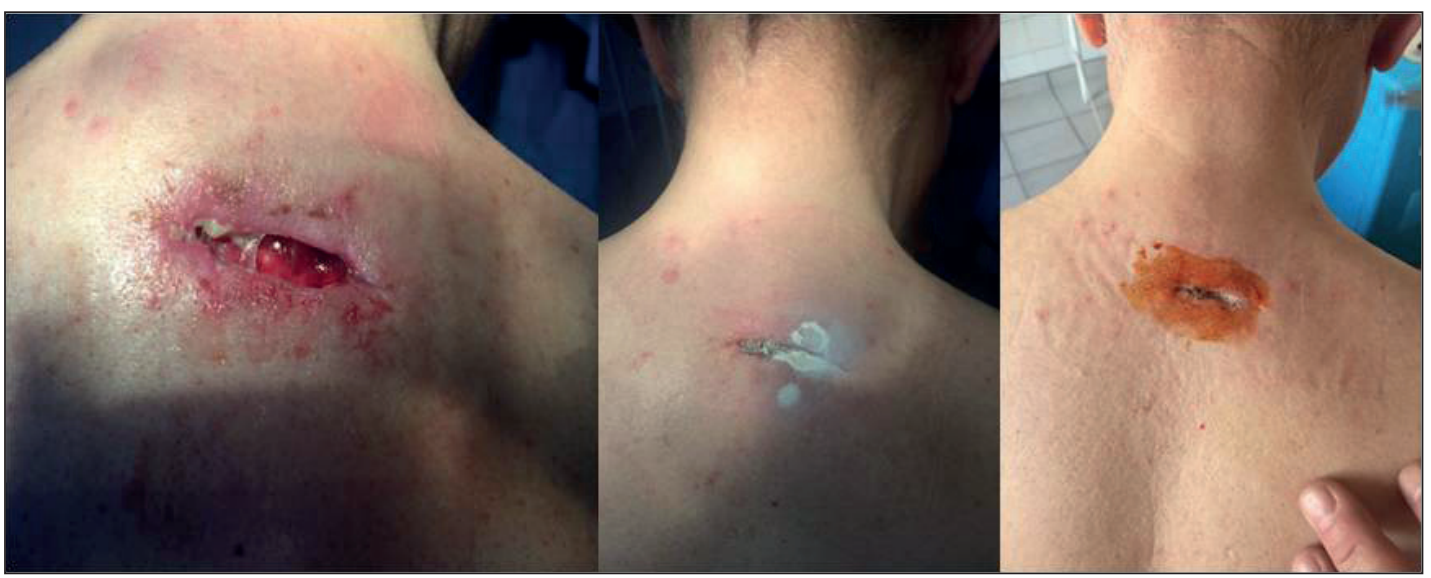

Fig. 2. An infected wound. Early dynamics. The treatment period is 11 days.

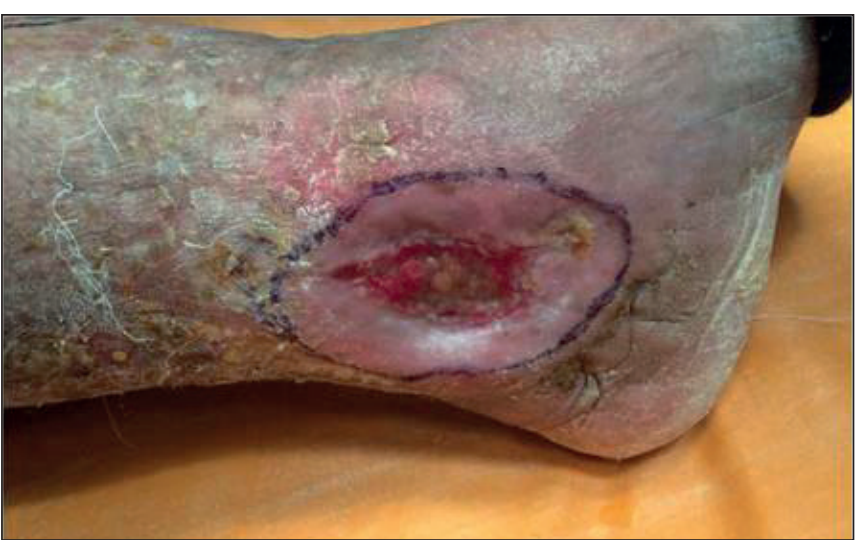

Fig. 3. Trophic ulcer of the shin. 14 days of treatment. Signs of regional epithelialization.

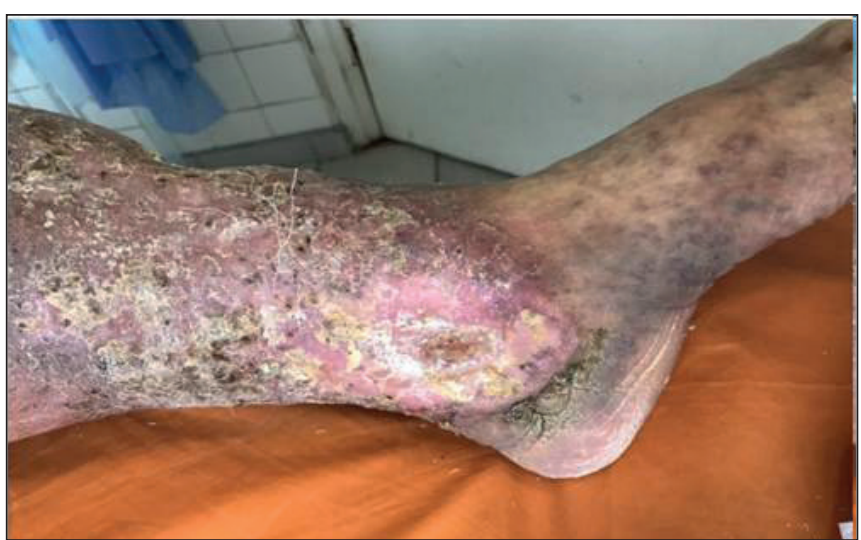

Fig. 4. Trophic ulcer of the shin. 19 days of treatment.

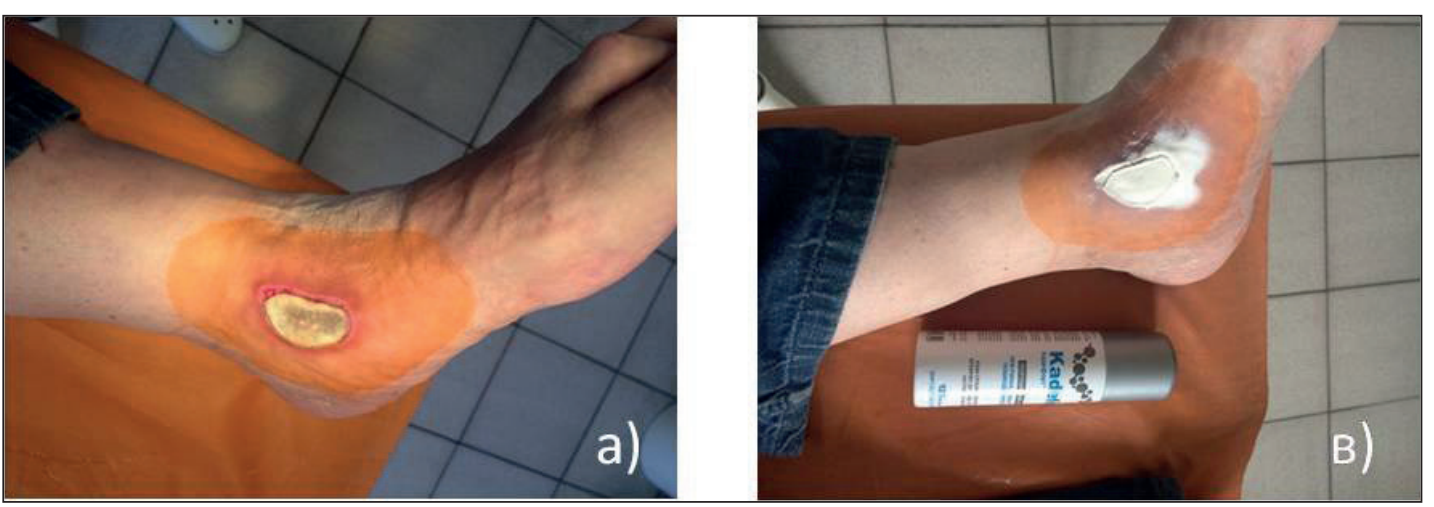

Fig. 5. a), b) Burning shin wound (thermal injury) 5 days of treatment. 

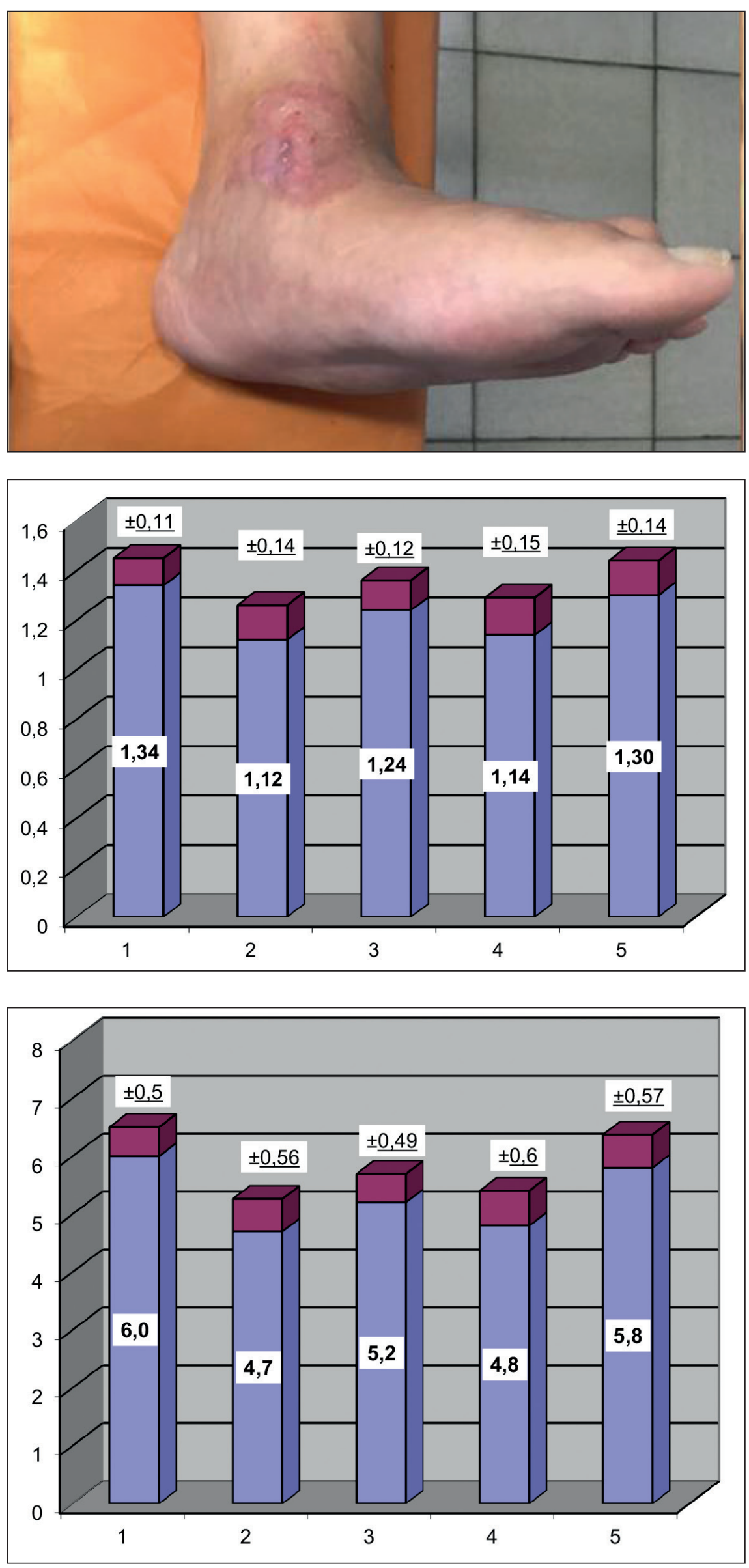

Pic. 6. Burning shin wound (thermal injury) 15 days of treatment.

Fig. 7. Dynamics of TX (CD-4) /TC (CD-8) in patients with long-term infected wounds: 1 - healthy; 2 - control group before treatment; 3 - control group after treatment; 4 - the main group before treatment; 5 - the main group after treatment.

Fig. 8. Dynamics of IgE in patients with longterm infected wounds: 1 - healthy; 2 - control group before treatment; 3 - control group after treatment; 4 - the main group before treatment; 5 - the main group after treatment 
6. Junker J.P.E., Kamel R.A., Grey E.J., et al. Harding Clinical impact upon wound healing and inflammation in moist, wet, and dry environments. Advances in wound care. 2013;2(7):238-354.

The work was carried out in the framework of research work D 55A20150454003305 «Monitoring of combined trauma in conditions of chronic iodine deficiency".

\section{ORCID and contributionship:}

Stepan S. Filip - 0000-0002-6549-3892 ${ }^{A, B, C}$

Rudolf M. Slivka - 0000-0002-0187-2711 ${ }^{\mathrm{C}}$

Yuriy P. Skripinets - 0000-0002-9741-4175 ${ }^{B, D}$

Andriy M. Bratasyuk - 0000-0003-4390-2357 ${ }^{E, F}$

Olena V. Fomenko-Luchinets - 0000-0002-2614-0883 B,C

\section{CORRESPONDING AUTHOR}

\section{Andriy M. Bratasyuk}

State Higher Educational Establishment «Uzhhgorod National University», Faculty of Postgraduate And Pre-University Education,

Sobranetska str. 148, 88015, Uzhhgorod, Ukraine

tel: +380677439445

e-mail:docbrat@gmail.com

Received: 17.01 .2020

Accepted: 05.03 .2020

A - Work concept and design, B - Data collection and analysis, C - Responsibility for statistical analysis, D-Writing the article, $\mathbf{E}$-Critical review, $\mathbf{F}$ - Final approval of the article 